\title{
Decreased hepatocellular carcinoma tumor burden with the achievement of hepatitis $C$ virus sustained virologic response: unlocking the potential of T-cell-mediated immunosurveillance
}

This article was published in the following Dove Press journal:

Journal of Hepatocellular Carcinoma

\author{
Anna S Griffith' \\ Paul H Hayashi' \\ Lauren MB Burke ${ }^{2}$ \\ Autumn J McRee' \\ 'Department of Medicine, \\ ${ }^{2}$ Department of Radiology, University \\ of North Carolina at Chapel Hill \\ Hospital, Chapel Hill, NC, USA
}

\begin{abstract}
We describe two cases of patients with hepatitis C virus (HCV) treated with directacting antiviral (DAA) therapy who had dramatic improvement in hepatocellular carcinoma (HCC) tumor burden with DAA therapy alone. Both patients were diagnosed with HCC on screening magnetic resonance imaging shortly after beginning DAA therapy. Both patients achieved sustained virologic response (SVR) with dramatic improvement in HCC tumor burden on follow-up imaging without HCC treatment. Patients with multifocal or advanced HCC are infrequently treated with antiviral therapy for $\mathrm{HCV}$. As a result, these cases provide unique insight into the ongoing debate regarding the impact of SVR on existing and recurrent HCC. We review the current literature regarding this debate, as well as the theory of immunosurveillance. We postulate that DAA therapy activates $\mathrm{CD} 8^{+} \mathrm{T}$ cells to induce a T-cell-mediated response and increased immunosurveillance to virus-induced liver cancer.
\end{abstract}

Keywords: hepatocellular carcinoma, hepatitis $\mathrm{C}$ virus, sustained virologic response, directacting antiviral, T-cell-mediated immunosurveillance

\section{Introduction}

Hepatocellular carcinoma (HCC) is an aggressive malignancy that occurs almost exclusively in patients with underlying liver disease. In the USA, hepatitis $\mathrm{C}$ is the cause of almost one-third of HCC cases and the incidence of $\mathrm{HCC}$ continues to rise. ${ }^{1}$ Direct-acting antivirals (DAAs) have revolutionized the treatment of chronic hepatitis $\mathrm{C}$ virus (HCV) infection, and now a cure, as defined by undetectable HCV RNA in the blood 12 weeks after treatment ends (sustained virologic response [SVR]), can be achieved in $>90 \%$ of patients. Retrospective data suggest that among HCV-infected patients, achieving SVR reduces the risk for a new HCC diagnosis. However, little is known about the effect of clearing the HCV on the prognosis of patients with preexisting HCC and some recently published larger studies ${ }^{2,3,11-13}$ suggest that DAA is not associated with a higher rate of HCC. ${ }^{2}$ Several recent publications have spurred the debate reporting that patients with $\mathrm{HCC}$ who are subsequently treated with DAA have a higher recurrence rate of HCC. ${ }^{3}$ We describe two HCV patients diagnosed with HCC whose tumor burden improved, not with any HCC-directed treatment, but with the achievement of SVR after DAA therapy.
Correspondence: Anna S Griffith Department of Medicine, University of North Carolina at Chapel Hill, NC 27514, USA

$\mathrm{Tel}+|919966| 459$

$\mathrm{Fax}+19198439355$

Email anna.griffith@unchealth.unc.edu 


\section{Case I}

A 56-year-old Brazilian female was first diagnosed with genotype $1 \mathrm{HCV}$ (subtyping not performed) after presenting with hematemesis. Endoscopy revealed grade 1 varices, and subsequent diagnostic work-up confirmed HCV RNA at 191,514 copies $/ \mathrm{mL}$. Pretreatment abdominal ultrasound showed no focal hepatic lesions. She was treated with a pangenotypic NS3/4A protease inhibitor-NS5A inhibitor combination on a clinical trial (Figure 1A). Five weeks after initiating HCV treatment, surveillance AFP levels rose from 37 to $434 \mathrm{ng} / \mathrm{mL}$. MRI of the abdomen performed at that time demonstrated regions of early arterial enhancement with late washout involving segments IV, V, and VIII with tumor thrombus into the left portal vein (Figure 1A) as well as a separate $1.3 \mathrm{~cm}$ lesion with early arterial enhancement and washout in the caudate lobe, consistent with diffuse HCC. Bilateral lower lobe pulmonary nodules measuring up to $1.1 \mathrm{~cm}$ were also identified, highly suspicious for pulmonary metastases. As per study protocol, HCV therapy was discontinued at that time, although she was HCV RNA negative at 6 weeks of treatment. Given that she had well-compensated Child-Pugh Class A cirrhosis, a well-preserved performance status, and stage IV HCC, she was offered palliative sorafenib with plans to repeat imaging at 3 months to assess response to therapy. However, before treatment was initiated, a repeat pretreatment MRI was obtained demonstrating an interval decrease in regions of abnormal arterial enhancement and washout as well as decreased portal venous tumor thrombus and resolution of the previously seen pulmonary metastases (Figure 2B). Her repeat AFP had decreased from 434 to $7.48 \mathrm{ng} / \mathrm{mL}$ in the same time frame (12 weeks after DAA therapy was discontinued). Given the radiographic improvement in disease burden, she has been monitored off therapy for 18 months without recurrent disease on follow-up MRI examinations. SVR has been durable.

\section{Case 2}

A 57-year-old Caucasian man was diagnosed with genotype 1A HCV cirrhosis in 1996 and was treated with 24 weeks of sofosbuvir/simeprevir $\sim 8$ years later. He relapsed after completing therapy and received 24 weeks of ledipasvir/sofosbuvir, achieving SVR after 6 weeks of therapy (Figure 1B). Two months after completing therapy, he underwent surveillance abdominal ultrasound that showed a new right hepatic lobe lesion. MRI of the abdomen at that time confirmed two separate masses in segments II and III measuring 2.0 and

A

ARI

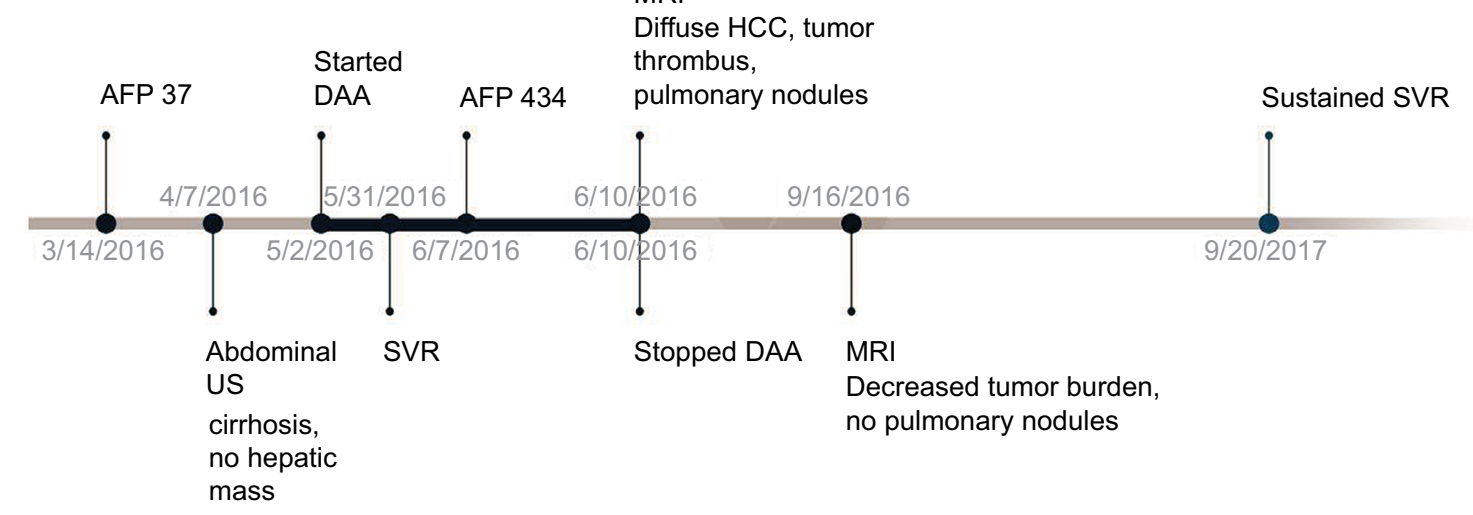

B

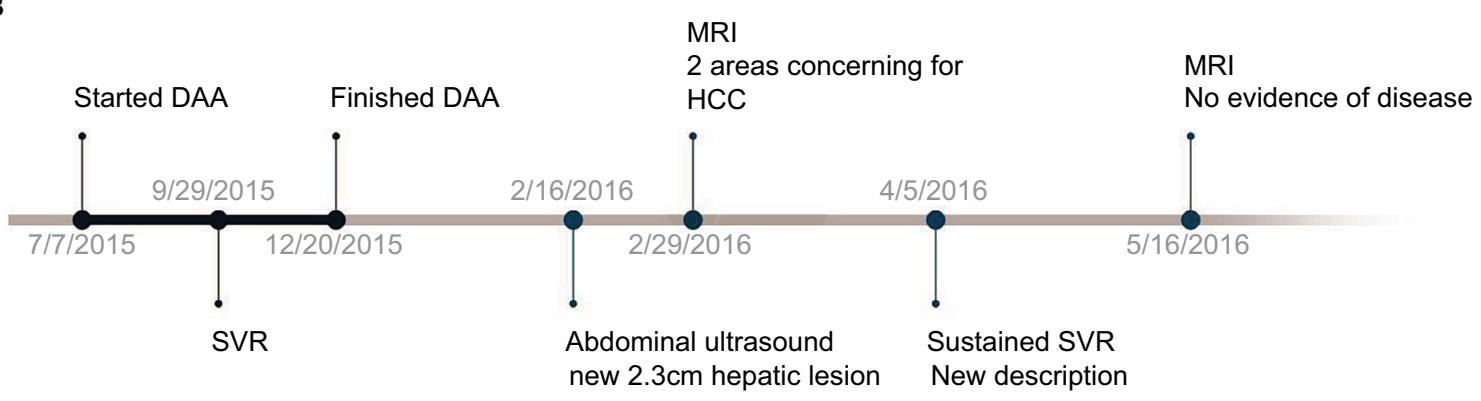

Figure I Timeline of events for (A) Case I and (B) Case 2.

Note: Temporal relationships between initiation of DAA, SVR documentation, cancer diagnosis, and radiographic studies.

Abbreviations: DAA, direct-acting antiviral; HCC, hepatocellular carcinoma; SVR, sustained virologic response; MRI, magnetic resonance imaging; US, ultrasound. 

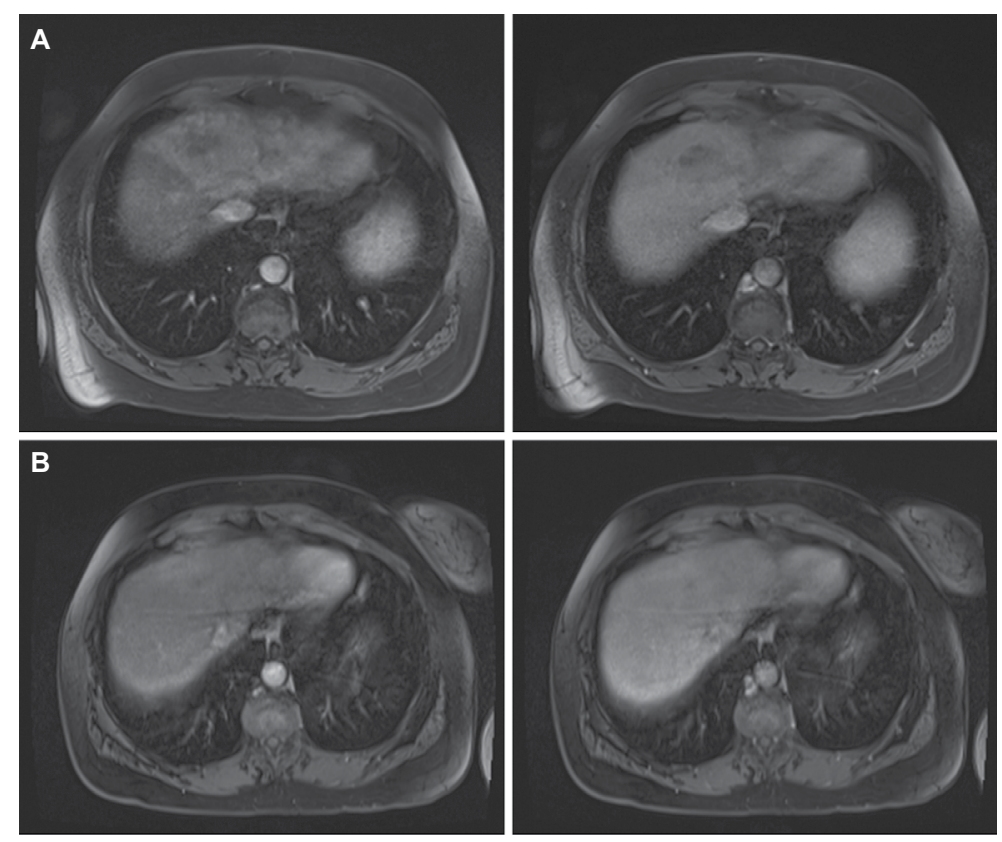

Figure 2 Interval MRI images from Case I.

Notes: (A) Early arterial and late portal venous phase fat-saturated postcontrast TI imaging demonstrating an early enhancing intrahepatic mass with washout involving segments IV, VII, and V consistent with diffuse HCC obtained at diagnosis. (B) Repeat early arterial and late portal venous phase fat-saturated postcontrast TI imaging obtained 12 weeks later with no subsequent HCC therapy demonstrating substantially decreased tumor burden.

Abbreviation: HCC, hepatocellular carcinoma.

$3.0 \mathrm{~cm}$, respectively, concerning for multifocal HCC, with associated abnormal nonmass-like arterial enhancement and washout seen throughout the right hepatic lobe (Figure 2A). He was referred to medical oncology for the consideration of liver-directed therapies; however, a pretreatment MRI was obtained and demonstrated interval resolution of the abnormal findings (Figure 3B), now 5 months after completing DAA therapy for HCV. He has remained on active surveillance for the last 20 months with four additional MRIs showing no radiographic evidence of HCC.

\section{Discussion}

There are various proposed mechanisms by which $\mathrm{HCV}$ induces HCC. It is well known that HCV leads to chronic inflammation, causing fibrosis and liver cell proliferation. In addition to the chronic inflammatory milieu created by the HCV, several oncogenic mechanisms have been studied and are well established. The basic mechanism of cancer development is related to an increase in liver cell turnover and oxidative damage, facilitating genetic alterations. These mutations have an array of effects, including activation of oncogenes and proliferation pathways, activation of telomerase, overexpression of growth factors, increased angiogenesis, and inactivation of tumor suppressor genes. ${ }^{4-9}$ The most well studied of these pathways include alterations of phospho-retinoblastoma ( $\mathrm{pRB}$ ), $\mathrm{p} 53$, transforming growth factor-beta, and beta-catenin pathways. Various viral proteins, most notably nucleocapsid core protein, NS3, and NS5A, have been implicated in oncogenesis and tumor progression.

There is much to be learned about the effect of treating chronic $\mathrm{HCV}$ in patients with concurrent HCC, and there is debate about the effect that achieving SVR has on the biology of existing and recurrent HCC. ${ }^{10-13}$ The study by Conti et al of patients with $\mathrm{HCV}$-cirrhosis treated with DAA reported an increase in de novo HCC occurrence and recurrence rates in the 24 weeks following the achievement of SVR when compared with patients who did not undergo treatment with DAA. The authors postulate that although the presumed etiology for cirrhosis and $\mathrm{HCC}$ was HCV, curing HCV decreases the level of immune surveillance in the liver, leading to a paradoxical increased risk of developing HCC. ${ }^{12}$ A second study by Reig et al also reports an unexpectedly high rate of tumor recurrence in patients with treated HCC (with resection, ablation, or chemoembolization) who achieved SVR with DAA. ${ }^{13}$ Of the 58 patients included in this retrospective analysis, $\sim 28 \%$ developed radiographic evidence of recurrence. A key distinction between these published reports and our two cases is that these publications studied de novo occurrence or recurrence rates of HCC after HCV treatment, not the impact of HCV 

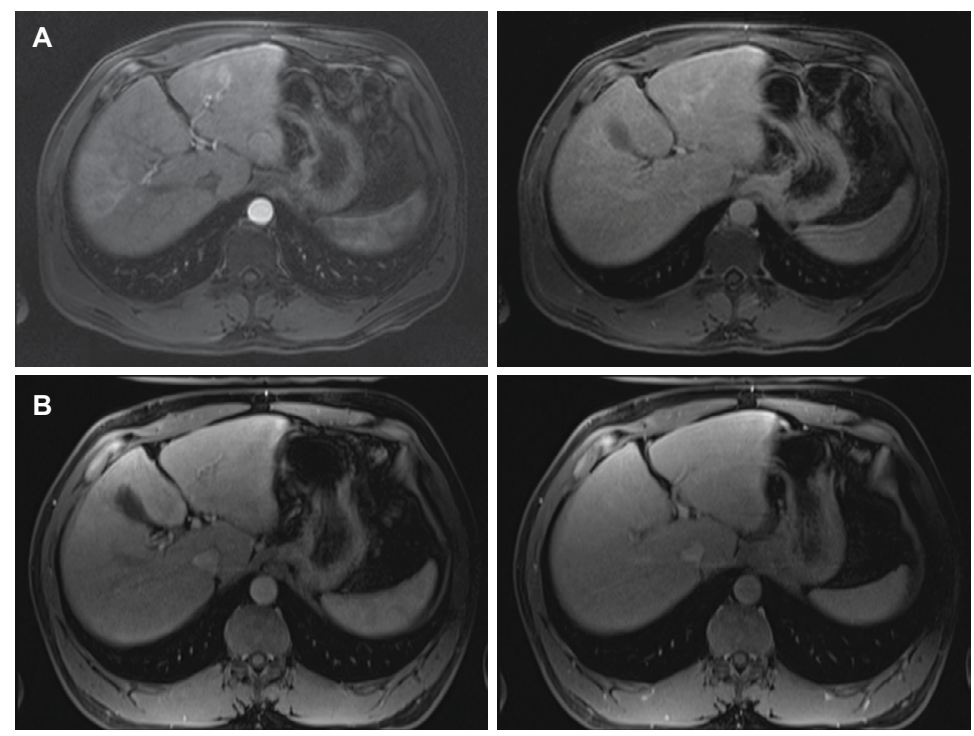

Figure 3 Interval MRI images from Case 2.

Notes: (A) Early arterial and late portal venous phase postcontrast fat-saturated TI-weighted MRI demonstrating a rim-enhancing lesion in segment III with washout and late capsular enhancement as well as diffuse increased arterial enhancement and washout seen throughout the right hepatic lobe. (B) Early arterial and late portal venous phase postcontrast fat-saturated TI-weighted MR imaging after a I2-week interval demonstrating normal hepatic parenchyma and no residual hepatic lesion.

Abbreviation: MRI, magnetic resonance imaging.

viral clearance on existing HCC. Moreover, other studies have called into question whether SVR truly increases the risk of HCC occurrence or recurrence. ${ }^{3,14-16}$

The two cases described in our report that of decreasing tumor burden and even resolution of presumed pulmonary metastasis with the treatment of HCV raises the possibility that with the clearance of $\mathrm{HCV}$, there is inhibition of $\mathrm{HCC}$ oncogenesis. Although there is debate about how HCV SVR mechanistically impacts the biology of $\mathrm{HCC}$, these cases raise an interesting question regarding the role of immunosurveillance in liver cancer. The theory of immunosurveillance is based on the complex ways in which the immune system and tumor cells interact, described in more detail as the following "Three E's" model: "elimination" of the cancer cells by the immune system, "equilibrium" during which the immune system and cancer cells coexist, and then, "escape" of the cancer with overt tumor progression. ${ }^{17}$ Chronic HCV infection is characterized by an activation of the innate immune system (as evidenced by increased natural killer [NK] cells and interferon stimulated genes) as well as a decrease in the adaptive immune system with suppressed $\mathrm{CD} 8^{+} \mathrm{T}$ cells. ${ }^{18}$ Treatment of HCV patients with DAA has been shown to modulate the composition of immune cells both in the liver and in circulation with the normalization of NK cell function and restoration of virus-specific $\mathrm{CD} 8^{+}$memory $\mathrm{T}$ cells. ${ }^{19,20}$ Expression of $\mathrm{CD} 8^{+} \mathrm{T}$ cells has been reported as a positive prognostic factor in HCC with high intratumoral densities correlating with lower rate of recurrences and longer disease-free survival times. ${ }^{21}$ Thus, curing a patient of SVR and reversing the inhibition of T-cell function potentially augment immune surveillance for HCC.

The dramatic improvement in disease burden described in these two cases raises the possibility that DAA treatment activating $\mathrm{CD} 8^{+} \mathrm{T}$ cells to respond to the $\mathrm{HCV}$ also induces a T-cell mediated response and increased immunosurveillance to the virus-induced aggressive HCC tumor. Ongoing large prospective cohorts of $\mathrm{HCV}$ patients treated with DAA are collecting longitudinal data that will ideally provide more clarity on how the interplay between viral elimination and immune surveillance effect $\mathrm{HCC}$ growth and identify cases similar to the two reported here..$^{22}$ As per our institutional standard, the University of North Carolina Institutional Review Board and Office of Human Research Ethics has reviewed this project. This case series does not constitute human subjects' research as defined under federal regulations; therefore, written consent from subjects is not required and IRB approval is not deemed necessary.

\section{Disclosure}

The authors report no conflicts of interest in this work.

\section{References}

1. Davila JA, Morgan RO, Shaib Y, McGlynn KA, El-Serag HB. Hepatitis $\mathrm{C}$ infection and the increasing incidence of hepatocellular carcinoma: a population-based study. Gastroenterology. 2004;127(5):1372-1380.

2. Bandiera S, Billie Bian C, Hoshida Y, Baumert TF, Zeisel MB. Chronic hepatitis $\mathrm{C}$ virus infection and pathogenesis of hepatocellular carcinoma. Curr Opin Virol. 2016;20:99-105. 
3. Li DK, Ren Y, Fierer DS, et al. The short-term incidence of hepatocellular carcinoma is not increased after hepatitis $\mathrm{C}$ treatment with directacting antivirals: an ERCHIVES study. Hepatology. Epub 2017 Dec 2.

4. Ozturk M. Genetic aspects of hepatocellular carcinogensis. Semin Liver Dis. 1999;19(3):325-342.

5. Moradpour D, Blum HE. Pathogenesis of hepatocellular carcinoma. Eur J Gastroenterol Hepatol. 2005;17(5):477-483.

6. Yamaguchi R, Yano H, Iemura A, Ogasawara S, Haramaki M, Kojiro M. Expression of vascular endothelial growth factor in human hepatocellular carcinoma. Hepatology. 1998;28(1):68-77.

7. Moriya K, Fujie H, Shintani Y, et al. The core protein of hepatitis C virus induces hepatocellular carcinoma in transgenic mice. Nat Med. 1998;4(9):1065-1067.

8. Sakamuro D, Furukawa T, Takegami T. Hepatitis C virus nonstructural protein NS3 transforms NIH 3T3 cells. JVirol. 1995;69(6):3893-3896.

9. Gale M Jr, Kwieciszewski B, Dossett M, Nakao H, Katze MG. Antiapoptotic and oncogenic potentials of hepatitis $\mathrm{C}$ virus are linked to interferon resistance by viral repression of the PKR protein kinase JVirol. 1999;73(8):6506-6516.

10. Nault JC, Colombo M. Hepatocellular carcinoma and direct-acting antiviral treatments: controversy after the revolution. $J$ Hepatol. 2016;65(4):663-665.

11. ANRS Collaborative Study Group on Hepatocellular Carcinoma (ANRS CO22 HEPATHER, CO12 CirVir and CO23 CUPILT Cohorts). Lack of evidence of an effect of direct-acting antivirals on the recurrence of hepatocellular carcinoma: data from three ANRS cohorts. J Hepatol. 2016;65(4):734-740.

12. Conti F, Buonfiglioli F, Scuteri A, et al. Early occurrence and recurrence of hepatocellular carcinoma in HCV-related Cirrhosis treated with direct-acting antivirals. J Hepatol. 2016;65(4):727-733.
13. Reig M, Marino Z, Perelló C, et al. Unexpected high rate of early tumor recurrence in patients with $\mathrm{HCV}$-related $\mathrm{HCC}$ undergoing interferonfree therapy. $J$ Hepatol. 2016;65(4):719-726.

14. Alberi A, Piovesan S. Increased incidence of liver cancer after successful DAA treatment of chronic hepatitis C: fact or fiction? Liver Int. 2017;37(6):802-808.

15. Cammà $\mathrm{C}$, Cabibbo $\mathrm{G}$, Craxì $\mathrm{A}$. Direct antiviral agents and risk for HCC early recurrence: much ado about nothing. $J$ Hepatol. 2016;65(4):861-862.

16. Romano A, Capra F, Piovesan S, et al. Incidence and pattern of "de novo" hepatocellular carcinoma in $\mathrm{HCV}$ patients treated with oral DAAs. Hepatology. 2016;64(S1):10A.

17. Dunn GP, Old LJ, Schreiber RD. The immunobiology of cancer immunosurveillance and immunoediting. Immunity. 2004;21(2):137-148.

18. Knolle PA, Thimme R. Hepatic immune regulation and its involvement in viral hepatitis infection. Gastroenterology. 2014;146(5):1193-1207.

19. Serti E, Chepa-Lotrea X, Kim YJ, et al. Successful Interferon-free therapy of chronic hepatitis $\mathrm{C}$ virus infection normalizes natural killer cell function. Gastroenterology. 2015;149(1):190-200.

20. Martin B, Hennecke N, Lohmann V, et al. Restoration of HCV-specific CD8+ T cell function by interferon-free therapy. J Hepatol. 2014;61(3): 538-543.

21. Gabrielson A, Wu Y, Wang H, et al. Intratumoral CD3 and CD8 T-cell densities associated with relapse-free survival in HCC. Cancer Immunol Res. 2016;4(5):41930.

22. Terrault NA, Zeuzem S, DiBisceglie AM, et al; HCV-TARGET Study Group. Effectiveness of ledipasvir-sofosbuvir combination in patients with hepatitis $\mathrm{C}$ virus infection and factors associated with sustained virologic response. Gastroenterology. 2016;151(6):1131-1140.
Journal of Hepatocellular Carcinoma

\section{Publish your work in this journal}

The Journal of Hepatocellular Carcinoma is an international, peerreviewed, open access journal that offers a platform for the dissemination and study of clinical, translational and basic research findings in this rapidly developing field. Development in areas including, but not limited to, epidemiology, vaccination, hepatitis therapy, pathology and

\section{Dovepress}

molecular tumor classification and prognostication are all considered for publication. The manuscript management system is completely online and includes a very quick and fair peer-review system, which is all easy to use. Visit http://www.dovepress.com/testimonials.php to read real quotes from published authors. 